\title{
Encapsulation and Survival of a Chondrocyte Cell Line within Xanthan Gum Derivative ${ }^{a}$
}

\author{
Ana C. Mendes, ${ }^{*}$ Erkan T. Baran, Rui C. Pereira, Helena S. Azevedo, Rui L. Reis
}

A chemical derivative of xanthan gum polysaccharide is investigated as a new artificial matrix for the encapsulation of chondrocytic cells. Toward this goal, a novel micro-droplet generator is developed to produce microcapsules. Microcapsules with an average diameter of $500 \mu \mathrm{m}$, smooth surface, and homogeneous size distribution are obtained. ATDC5 cells encapsulated in carboxymethyl xanthan (CMX) microcapsules remain viable and are observed to proliferate for prolonged culture periods with enhanced metabolic activity. Furthermore, retention of the chondrogenic phenotype is exhibited by the cells within CMX, suggesting the ability of this material to be applied in cell-delivery therapies.

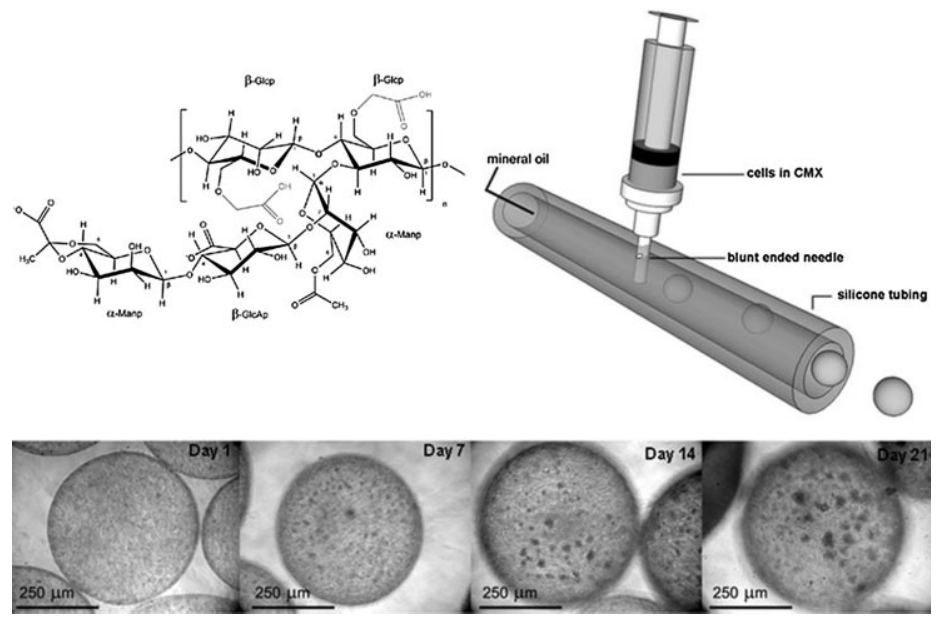

\section{Introduction}

Cell microencapsulation is a technology with enormous clinical potential for the treatment of a wide range of human diseases such as diabetes, ${ }^{[1-3]}$ hemophilia, anemia, hypoparathyroidism, renal failure ${ }^{[1,4-7]}$ osteoarthritis, ${ }^{[8-14]}$ and also for constructing artificial organs. ${ }^{[1]}$ In cell encapsulation, cells are protected from immune rejection

A. C. Mendes, E. T. Baran, R. C. Pereira, H. S. Azevedo, R. L. Reis 3B's Research Group - Biomaterials, Biodegradables and Biomimetics, University of Minho, Headquarters of the European Institute of Excellence on Tissue Engineering and Regenerative Medicine, AvePark, 4806-909 Taipas, Guimarães, Portugal, and ICVS/3B's PT Government Associate Laboratory, Braga/ Guimarães, Portugal

E-mail: ana.mendes@dep.uminho.pt

\footnotetext{
a Supporting Information for this article is available from the Wiley Online Library or from the author.
}

by an artificial, semipermeable membrane, potentially allowing transplantation (allo- or xenotransplantation) without the need for immunosuppression. ${ }^{[1,4-7,15-18]}$ For the clinical success of cell encapsulation, it is crucial to have a source of cells, a biocompatible, as well as mechanically and chemically stable membrane of suitable permeability, which is able to provide immune protection to the implant. $^{[1,4-6,15,16]}$ Although efforts have been made in order to accomplish these goals, the available systems still present limitations regarding their reproducibility during microcapsule preparation and long-term viability of encapsulated cells. During the past decade, several polyelectrolytes, such as polysaccharides and polypeptides, have been widely used for the fabrication of capsules, due their ability to form gels through complexation with oppositely charged polymers (e.g., alginate/poly-L-lysine $(\mathrm{PLL})^{[3,17]}$ ) or by ionic crosslinking of the polyanionic biopolymer in the presence of a counterion (e.g., $\mathrm{Ca}^{2+}$, $\left.\mathrm{Ba}^{2+}\right)$. In these cases, the gelation processes is cell- 
compatible, since they do not require harsher chemicals, and the gels provide a highly hydrated three-dimensional (3D) network. Furthermore, these materials can be injected into the body, hence enabling the clinician to transplant the cell-polymer combination in a minimally invasive way. ${ }^{[19]}$

Cell based therapies have demonstrated an enormous potential for the long term repair of cartilage defects ${ }^{[8-14]}$ and the alginate-based hydrogels have been widely used as a convenient 3D cell culture model system. ${ }^{[9-11,13,20,21]}$ This system has demonstrated the ability to prevent chondrocytes from undergoing de-differentiation as well as restore cartilaginous phenotype to de-differentiated chondrocytes. ${ }^{[22]}$ In addition, alginate systems have shown to promote the synthesis of cartilage matrix components, such as proteoglycans and collagen type II. ${ }^{[21,23]}$

Although alginate/PLL polyelectrolyte complexes have been widely investigated for cell encapsulation, they still present some drawbacks concerning their long-term mechanical performance and biocompability. ${ }^{[7,24]}$

Xanthan gum is an extracellular polysaccharide produced by the bacterium Xanthomonas campestris. ${ }^{[25-28]}$ The primary structure of xanthan consists of $\beta(1 \rightarrow 4)$-linked glucose units, similar to the structure of cellulose backbone, substituted at $\mathrm{O}-3$ of alternate glucose residues, with a trisaccharide. The trisaccharide consists of one glucuronic acid unit between two mannose units (Figure 1a). The terminal mannose moiety may carry pyruvate residues linked to the positions 4 and 6 with an unknown distribution. D-Mannose unit linked to the main chain contains an acetyl group at position 0-6. ${ }^{[25-29]}$ The pyruvic acid content of xanthan can vary substantially depending on the strain of $X$. campestris, resulting in different viscosities of xanthan solutions. Molecular modeling studies suggest that xanthan gum can assume a helical structure, with the side branches positioned almost parallel to the helix axis and stabilizing the structure. ${ }^{[25-27,29]}$ The presence of acetic and pyruvic acids is the main responsible for the polyanionic character of this polysaccharide. Xanthan forms very viscous solutions, and, at sufficiently high polymer concentration, it exhibits weak gel-like properties. ${ }^{[25,30]}$ Furthermore, it was shown to be biocompatible, ${ }^{[28]}$ biodegradable and it is widely used in food, cosmetics, and pharmaceuticals because of its encouraging reports on safety. ${ }^{[25]}$

The application of other microbial polysaccharides with gelling properties, such as gellan gum, has been reported in the literature for the encapsulation of human chondrocytes for cartilage regeneration ${ }^{[31]}$ but to the best of our knowledge, the use of xanthan gum as cell encapsulation matrix has only been described by our group. ${ }^{[32]}$ Therefore, the present work aims to investigate the potential of a xanthan derivative [carboxymethyl xanthan (CMX)] as a new matrix for the encapsulation of ATDC5 cell line which has been widely used as a model to study chondrogenic differentiation in vitro. ${ }^{[33-37]}$ To test our hypothesis, we have used a simple microdroplet generator, based on a tubing system, to produce microcapsules with homoge- 
neous size distribution and micrometer size favorable for mass transfer and easy injects for cell therapy. In vitro studies were performed to evaluate the ability of the CMX microcapsules to support cell viability, proliferation, and cell functions.

\section{Experimental Section}

\subsection{Materials}

All chemicals, including xanthan gum from $X$. campestris, monochloroacetic acid, and poly-i-lysine, were obtained from Sigma-Aldrich unless otherwise indicated. The chemicals were used as received.

\subsection{Determination of Molecular Weight of Native Xanthan}

The average molecular weight $\left(\bar{M}_{\mathrm{W}}\right)$ was determined by sizeexclusion chromatography (SEC). The samples were dissolved in an aqueous $0.1 \mathrm{M} \mathrm{NaNO}$ solution ( $0.4 \% \mathrm{w} / \mathrm{v})$. A PL-GPC 110 chromatograph was equipped with a pre-column PLaquagel-OH $15 \mu \mathrm{m}$ and two SEC columns in series (PLaquagel-OH40 $15 \mu \mathrm{m}, 300 \times 7.0 \mathrm{~mm}^{2}$ and PLaquagel-OH60 $15 \mu \mathrm{m}, 300 \times 7.0 \mathrm{~mm}^{2}$ ). The pre-column, the SEC columns, the injection system, and the refractive index detector were maintained at $36^{\circ} \mathrm{C}$. The eluent (aqueous $0.1 \mathrm{M} \mathrm{NaNO}_{3}$ solution) was pumped at a flow rate of $0.9 \mathrm{~mL} \cdot \mathrm{min}^{-1}$. The analytical columns were calibrated with pullulan standards (Polymer Laboratories, UK) in the range of $5.8-1600 \mathrm{kDa}$. The average molecular weight of xanthan gum was estimated as $152 \mathrm{kDa}^{[32]}$

\subsection{Synthesis}

CMX was prepared by adapting the carboxmethylation procedure used for chitosan by Chen and Park. ${ }^{[38]} 10 \mathrm{~g}$ of xanthan from $X$. campestris and $13.5 \mathrm{~g}$ sodium hydroxide (Panreac, Spain) were mixed in $100 \mathrm{~mL}$ of solvent mixture of water/isopropyl alcohol (Fluka, Germany) using a top stirrer. The mixture was allowed to react at $50^{\circ} \mathrm{C}$ in a water bath (Thermostat IKA, Germany) for $1 \mathrm{~h}$. Two solvent mixtures were used (1:1 and 1:4 v/v) to yield xanthan with different degrees of carboxymethylation designated by CMX1 and CMX2, respectively. Then, $15 \mathrm{~g}$ monochloroacetic acid, dissolved in $20 \mathrm{~mL}$ of isopropyl alcohol, were added dropwise to the reaction mixture for $30 \mathrm{~min}$. The reaction was carried out for $4 \mathrm{~h}$ at the same temperature and stopped by adding $200 \mathrm{~mL}$ of ethanol $70 \%$ (Panreac, Spain). At the end, the obtained solid precipitate was filtered and rinsed with $70-90 \%$ of ethanol to desalt and dewater and further vacuum dried at room temperature.

\subsection{Characterization}

\subsubsection{FTIR Spectroscopy}

The chemical modification of xanthan was analyzed by infrared spectroscopy in an IR Prestige-21 (SHIMADZU, Japan) spectro- photometer. Prior to analysis, potassium bromide ( $\mathrm{KBr}$, PIKE Techonologies, USA) pellets were prepared by mixing the CMX powder with $\mathrm{KBr}(\mathrm{CMX} / \mathrm{KBr}, 1: 10 \mathrm{w} / \mathrm{w})$. The spectrum was taken with the average of 32 scans and a resolution of $4 \mathrm{~cm}^{-1}$.

\subsubsection{Determination of the Degree of Substitution (DS)}

The DS of CMX was determined by acid/base titration. CMX (0.2 g) was dissolved in $40 \mathrm{~mL}$ of distilled water. The $\mathrm{pH}$ of the solution was adjusted to 2 with hydrochloric acid and then CMX was titrated with $0.1 \mathrm{~N} \mathrm{NaOH}$. The volume of added $\mathrm{NaOH}$, as well as the $\mathrm{pH}$ values, were recorded. Three replicates were performed for each sample. DS was calculated following the calculation procedure used for carboxymethyl chitosan and described by Ge and Luo ${ }^{[39]}$ as follows:

$$
\mathrm{DS}=\frac{M_{\mathrm{Xru}} \times\left(n_{\mathrm{ep}}\right)}{0.2-\left(M_{\mathrm{CM}} \times n_{\mathrm{ep}}\right)}
$$

where $M_{\text {Xru }}$ is the molecular weight of Xanthan repeating unity (851), $n_{\mathrm{ep}}$ the number of mol of carboxymethyl groups at the ending point of the titration, and $M_{C M}$ is the molecular weight of the carboxymethyl groups inserted in the native structure of Xanthan gum.

\subsection{Cell Culture and Encapsulation}

The murine ATDC5 chondrocyte cells were cultured in basic medium, consisted of Dulbecoo's modified Eagle medium (DMEM, Sigma-Aldrich, USA) with phenol red, supplemented with $10 \%$ fetal calf serum (FCS, Biochrom AG, Germany), $5 \times 10^{-3}$ M L-glutamine (Sigma, USA) and $1 \%$ of antibiotic/antimycotic mixture (Sigma, USA) and maintained at $37^{\circ} \mathrm{C}$ in a humidified atmosphere of $5 \%$ $\mathrm{CO}_{2}$. The medium was replaced every $2 \mathrm{~d}$. At passage 7 , cells were detached with trypsin/ethylenediamine tetraacetate (EDTA) and counted in a hemacitometer for encapsulation.

The cells were encapsulated into CMX microcapsules using a novel in house micro-droplet generator ${ }^{[40]}$ as illustrated in Figure 2A. In this system, an autoclavable tubing (Novosil, Fisher Scientific, USA) with $1 \mathrm{~mm}$ internal diameter was punctured with a blunt end needle in a vertical position and sealed with a silicone glue. This assembly can be autoclaved numerously and can be assembled with peristaltic pump (Ismatec, Switzerland) and syringe pump (Alladdin WPI, England) as shown in Figure 2B. One end of the tubing was connected to an oil reservoir (Aldrich, Germany) and the other end to a glass collector where the droplets were cured in a crosslinker solution. A magnetic top stirring apparatus, made up of Teflon with a magnet, was placed on the top of collector in order to stir solution without introducing a mechanical stress on the formed microcapsules. The operation rate of peristaltic and syringe pump was set at $0.35 \mathrm{~mL} \cdot \mathrm{min}^{-1}$ and $20 \mu \mathrm{L} \cdot \mathrm{min}^{-1}$, respectively.

Prior to encapsulation, CMX powder (sterilized by autoclaving for $10 \mathrm{~min}$ at $121^{\circ} \mathrm{C}$ ) was dissolved in DMEM (5 wt\%) until obtaining a homogeneous solution. Subsequently, a cell suspension at cellular density of $10^{7}$ cells $\cdot \mathrm{mL}^{-1}$ was mixed with aqueous CMX solution. The microdroplets generated by the device were fed into the crosslinker solution containing $1.5 \% \mathrm{CaCl}_{2}$ (Merck Chemical Co.,

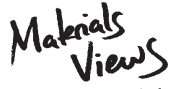

www.MaterialsViews.com
Macromol. Biosci. 2011, 11, 000-000

(C) 2011 WILEY-VCH Verlag GmbH \& Co. KGaA, Weinheim

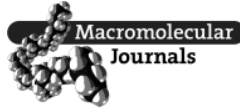



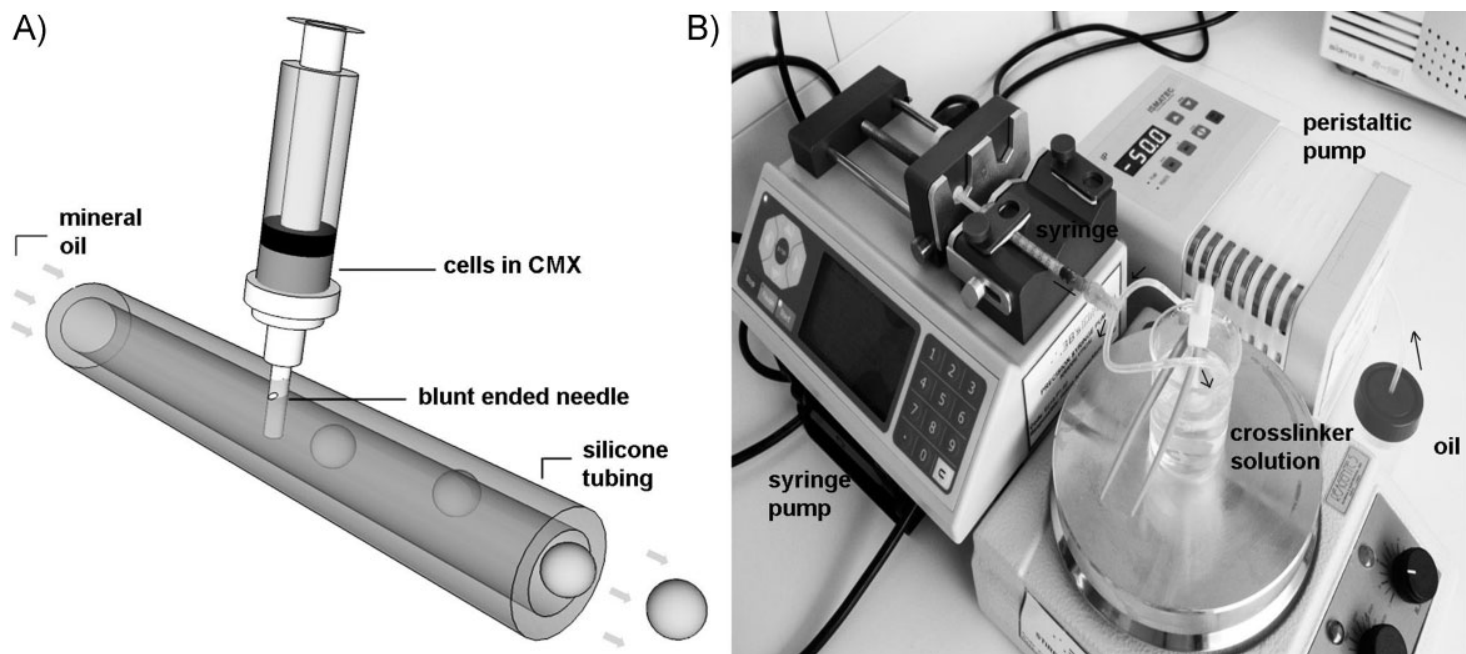

Figure 2. (A) Schematic representation of the micro-droplet generator. (B) Photograph showing the apparatus used to produce the microcapsules.

Germany) and 0.9\% $\mathrm{NaCl}$ (Carlo Erba, Italy) as shown in Figure 2B. The CMX capsules were stirred gently for $15 \mathrm{~min}$ and then washed with phosphate-buffered saline (PBS, Sigma, USA) in order to remove traces of mineral oil. Afterwards, the collected microcapsules were transferred into a PLL solution (0.1 wt\%, 30-70 kDa) for $10 \mathrm{~min}$ in order to strengthen the outer surface of the microcapsules. Finally, the coated microcapsules were transferred to DMEM culture medium and cultured in a 24-well polystyrene plate, previously coated with agarose ( $4 \mathrm{wt} \%$ in PBS) to avoid the adhesion of non-encapsulated cells.

Alginate (alginic acid sodium salt from brown algae, $\bar{M}_{\mathrm{w}}=100 \mathrm{kDa}$, Fluka, Norway) was used to produce microcapsules to serve as controls. They were also produced following a procedure similar to the one described for CMX microcapsules. The alginate microcapsules were successively coated with the PLL (0.05 wt\%) for 5 min (see Supporting Information).

The encapsulated cells $(n=3)$ were maintained in vitro culture for a period of 3 weeks in DMEM with media exchange every $2 \mathrm{~d}$. Empty microcapsules were also maintained throughout the culture period to serve as controls.

\subsubsection{Microcapsule Characterization}

\section{Light Microscopy}

Microscopic observations of the encapsulated cells and controls were carried out over the course of the in vitro culture to examine the cell morphology and growth. A bright field light microscope (AXIOVERT 40 CFL, Zeiss, Germany) equipped with a digital camera (Canon Power shot G8, Japan) was used and images were acquired at $10 \times$ magnification.

\section{Scanning Electron Microscopy (SEM)}

Prior to the SEM observations, the microcapsules were fixed with glutaraldehyde (Electron Microscopy Sciences, USA) solution (3 vol\% in PBS) at $4{ }^{\circ} \mathrm{C}$ for $1 \mathrm{~h}$. The samples were further dehydrated in a graded ethanol series $(20,50,60,70,80,90$, and $100 \%)$ followed by immersion in 100\% hexamethyldisilazane (HMDS, Electron Microscopy Sciences, USA). Microcapsules were cut in half to expose the membrane cross-section and the internal surface of microcapsules. The specimens were mounted on aluminum stubs and sputter coated with Pt/Pd target $(80: 20)$ generating a thin film with $6 \mathrm{~nm}$ of thickness (208 HR High Resolution Sputter Coater, Cressington). The microcapsules were imaged on an ultra-high resolution field-emission gun scanning electron microscope (FEGSEM, FEI Nova 200 NanoSEM).

\section{Cell Viability and Proliferation Post-Ecapsulation}

To investigate if the CMX microcapsules can support cell viability and proliferation, encapsulated cells were examined using several biochemical analyses. Viability of cells was assessed by fluorescence microscopy using a live/dead assay; the metabolic activity of the encapsulated cells was analyzed by the AlamarBlue assay and cell proliferation evaluated by DNA quantification.

\section{Live/Dead Cell Assay}

Calcein AM (Sigma, USA) solution (2:1000 v/v) was prepared in DMEM medium without FCS and phenol red. Propidium iodide (PI, Molecular Probes, Invitrogen, USA) solution was prepared by mixing $2 \mu \mathrm{L}$ PI $\left(1 \mathrm{mg} \cdot \mathrm{mL}^{-1}\right)$ with $20 \mu \mathrm{L}\left(1 \mathrm{mg} \cdot \mathrm{mL}^{-1}\right)$ RNAse A (USB corporation, USA) and $2 \mathrm{~mL}$ PBS. The microcapsules with encapsulated cells and controls were collected from the culturing plates and incubated with calcein-AM and PI solutions at $37^{\circ} \mathrm{C}$ for $10 \mathrm{~min}$ protected from light. Samples were then observed under fluorescent microscopy using an Axioplan Imager Z1m microscope (Zeiss, Germany).

\section{Metabolic Activity of Encapsulated Cells - AlamarBlue ${ }^{\circledR}$ Assay}

The metabolic activity of encapsulated cells over time was assessed using the AlamarBlue assay (AbD Serotec, UK). AlamarBlue was added ( $10 \%$ of the volume of the well) to each well containing the encapsulated cells and the plate was incubated at $37^{\circ} \mathrm{C}$ for $20 \mathrm{~h}$ 
protected from light. After incubation, $100 \mu \mathrm{L}$ of solution was taken from each well and placed in a 96 well plate. The absorbance was read at 570 and $600 \mathrm{~nm}$ on a microplate reader (BioTek, Synergy HT, USA). The percentage of reduced AlamarBlue was calculated according the manufacturer instructions.

\section{Cellular Proliferation Assay}

ATDC5 proliferation within the capsules was determined using a fluorimetric dsDNA quantification kit (PicoGreen, Molecular Probes, Invitrogen, USA). For this purpose, the samples collected at days 1, 7, 14, and 21 were washed twice with sterile PBS (Sigma, USA) solution and transferred into $1.5 \mathrm{~mL}$ microtubes containing $1 \mathrm{~mL}$ of ultra-pure water. Capsules with and without cells were stored at $-80^{\circ} \mathrm{C}$ until further analysis. Prior to DNA quantification, samples were thawed and broken by pipetting up and down using a syringe with a needle to cause material disruption and facilitate DNA extraction. 28.7 $\mu \mathrm{L}$ of each sample and standards $\left(0-2 \mathrm{mg} \cdot \mathrm{mL}^{-1}\right)$ were transferred to an opaque 96 well plate. Then $71.3 \mu \mathrm{L}$ of PicoGreen solution and $100 \mu \mathrm{L}$ of Tris/EDTA buffer were added. Standards and samples were prepared in triplicate. The plate was incubated for $10 \mathrm{~min}$ in the dark and the fluorescence was measured using an excitation wavelength of $485 \mathrm{~nm}$ and emission of $528 \mathrm{~nm}$. DNA amounts were calculated from the calibration curve.

\section{Histology}

Cell cultured microcapsules for histology were rinsed three times in PBS and then fixed in $3.7 \%$ formalin in PBS for $1 \mathrm{~h}$ at room temperature. After fixation, samples were dehydrated in a graded ethanol series (70, 90, 95, and 100\%) followed by immersion in xylene. Specimens were embedded in paraffin and cut in $4 \mu \mathrm{m}$ thick sections (Microm HM355S Microtome, Inopat, USA). Sections were then dewaxed and stained with Harris Hematoxylin (Sigma, USA) and eosin (H\&E staining).

\subsection{Statistical Analysis}

Results of DNA quantification and cell viability are expressed as a mean \pm standard deviation with $n=3$ for each group. Statistical significance of differences was determined using unpaired student's $t$-test multiple comparison procedure at a confidence level of $95 \%(p<0.05)$.

\section{Results and Discussion}

\subsection{Characterization}

When designing materials for cell encapsulation, several properties should be considered. For instance, the amount and the character of functional groups contained in monomer units will influence the intermolecular interactions and consequently complex formation. Complexation is enhanced by the charge density in the polyanion, which depends on the chemical structure, the $\mathrm{p} K_{\mathrm{a}}$ of the polyelectrolyte, as well the $\mathrm{pH}$ of the solution. Xanthan by itself is able to form self-supporting gels in the presence of ions, although they are not stable in presence of aqueous

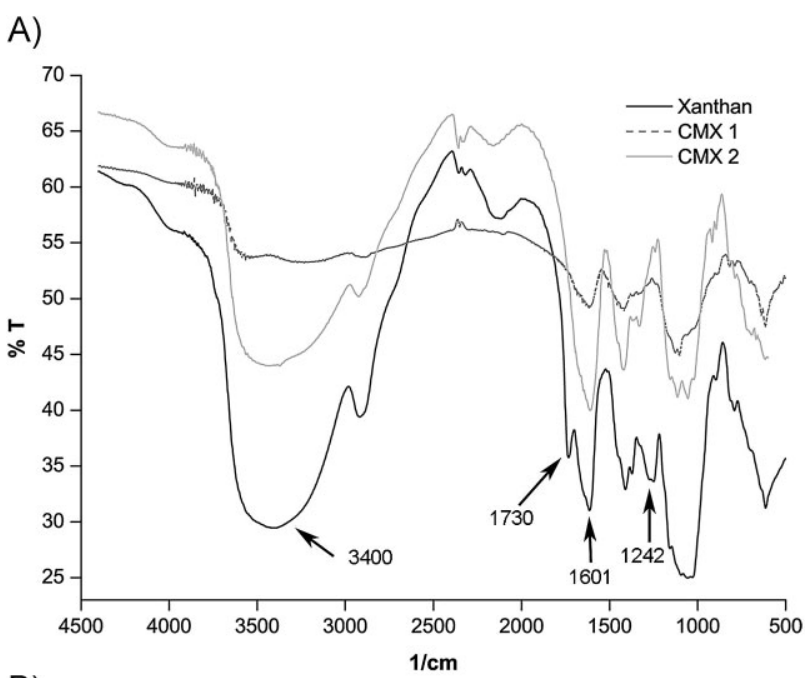

B)

\begin{tabular}{cc}
\hline Sample designation & Degree of substitution \\
\hline CMX1 & $0.35 \pm 0.1$ \\
CMX2 & $4.38 \pm 0.1$ \\
\hline
\end{tabular}

Figure 3. (A) FTIR spectra of native xanthan and carboxymethylated xanthans with different degrees of modification (CMX 1 and CMX2). (B) DS obtained from acid/base titration.

solutions in the long term. For increasing gel stability, xanthan was carboxymethylated and its chemical composition was characterized in order to control capsule properties and performance in biological solutions. The chemical modification on xanthan was confirmed by FTIR spectra (Figure 3A) by the decrease of the $\mathrm{C}-\mathrm{O}-\mathrm{H}$ band intensity at $1425 \mathrm{~cm}^{-1}$ and $\mathrm{O}-\mathrm{H}$ stretching at $3400 \mathrm{~cm}^{-1}$. In addition, the absorption band at $1616 \mathrm{~cm}^{-1}$, attributed to $\mathrm{C}=\mathrm{O}$ groups of pyruvate, was increased significantly after carboxymethylation, while the carbonyl peak, which is provided by the acetate at $1741 \mathrm{~cm}^{-1}$ in native xanthan, was not observed in CMX. This may indicate that the acetyl group was hydrolyzed by sodium hydroxide during carboxymethylation and consequently converted into carboxymethyl group.

Comparing the spectra of modified xanthans, CMX2 presents more evident changes than CMX1 when compared with native xanthan, indicating higher level of modification. To confirm this hypothesis, we determined the DS which was found to be higher for CMX2 (4.38) than for CMX1 (0.35) (Figure 3B). Due to the higher DS of CMX2 and its ability to form gels, we selected this carboxymethylated xanthan for subsequent encapsulation studies.

\subsection{Microcapsule Preparation and Encapsulation of Cells}

A simple microencapsulation process was developed by using a silicone tubing and blunt ended syringe needle

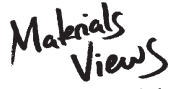

www.MaterialsViews.com
Macromol. Biosci. 2011, 11, 000-000

(C) 2011 WILEY-VCH Verlag GmbH \& Co. KGaA, Weinheim

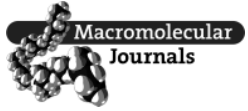




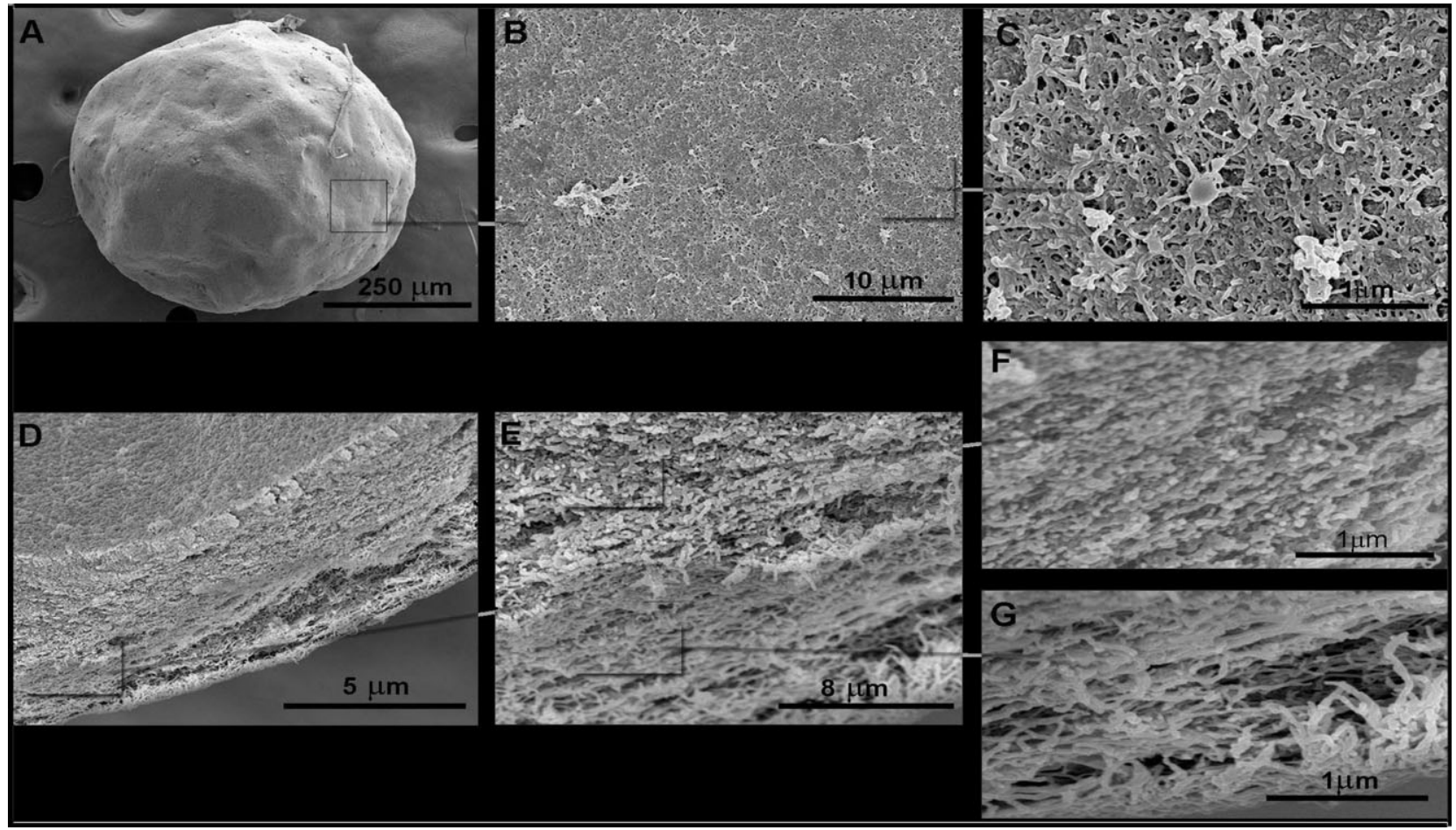

Figure 4. SEM images showing the overall structure of $C M X$ microcapsules (A), the microstructure of the microcapsule external surface $(B, C)$ and cross-section of microcapsule membrane (D). (E) Zoom/in of (D) showing the interface between CMX and PLL complex. $(F, G)$ Magnified images revealing morphological details of CMX and PLL layers, respectively.

which can be prepared in biology laboratories without need for advance techniques and skills which are required for preparation of microfluidic devices. The size of microcapsules can be adjusted by using tubing at desired internal diameter that are commercially available in wide size range. The device can be sterilized by autoclaving and connected to pumps easily on aseptic conditions. The first step of microcapsule formation is the extrusion of the polymer solution through the micro-droplet generator which enables a homogeneous size distribution. The microcapsules were then formed by crosslinking of generated droplets in a crosslinking solution while preserving physiological conditions for cells.

The morphology and microstructure of the microcapsules were analyzed using SEM (Figure 4). Capsules with spherical shape and a diameter of $500 \mu \mathrm{m}$ were obtained. At higher magnifications (Figure 4B, C) the microcapsule external surface appears to be quite smooth. Their relatively small and uniform size (high surface to volume ratio) has been considered advantageous under a mass transport and immunological response perspectives. ${ }^{[4,15,16,41]}$ At the same time, capsules with rough surfaces should be avoided since they can elicit immunological reactions when implanted. ${ }^{[15,41]}$

SEM images of the microcapsule cross-sections (Figure 4D) reveal an amorphous membrane with thickness of about $5 \mu \mathrm{m}$ and two layers with distinct morphologies.
The magnified photos highlighted a fibrous structure which results in a porous matrix. The Image J software (NIH, USA) analysis showed that those structures have highly conserved dimension with the mean width of $35.97 \pm 6.3$ (Figure 4C) and $29.89 \pm 6.9 \mathrm{~nm}$ (Figure 4G) from capsule surface and cross-sectioned area of microcapsule wall, respectively. This result may indicate that the complex formation between PLL and CMX might be affected by macromolecular tertiary structure of both biopolymers and as a result, reproducible tubular structures were formed. A successful capsule membrane for cell transplantation should allow rapid diffusion of nutrients, wastes, and important metabolic products. From those fibrous network structures it can be expected that the capsule wall can be quite permeable to nutrients and permit high viability conditions for encapsulated cells inside microcapsule. Moreover, it is expected that the permeability of the capsules can be controlled by changing the degree of modification of xanthan, the concentration and molecular weight of both polymers (xanthan and PLL).

Cytotoxicity is an important criterion for any biomaterials used in tissue engineering. We analyzed the cytotoxicity of the CMX capsules over ATDC5 cells via MTS [3(4,5-dimethylthiazol-2-yl)-2-(4-sulfophenyl)-2H-tetrazolium salt] assay (data not shown). Cells were exposed to the extracts from CMX capsules in contact with culture medium for 24,48 , and $72 \mathrm{~h}$. Latex rubber extract and fresh 

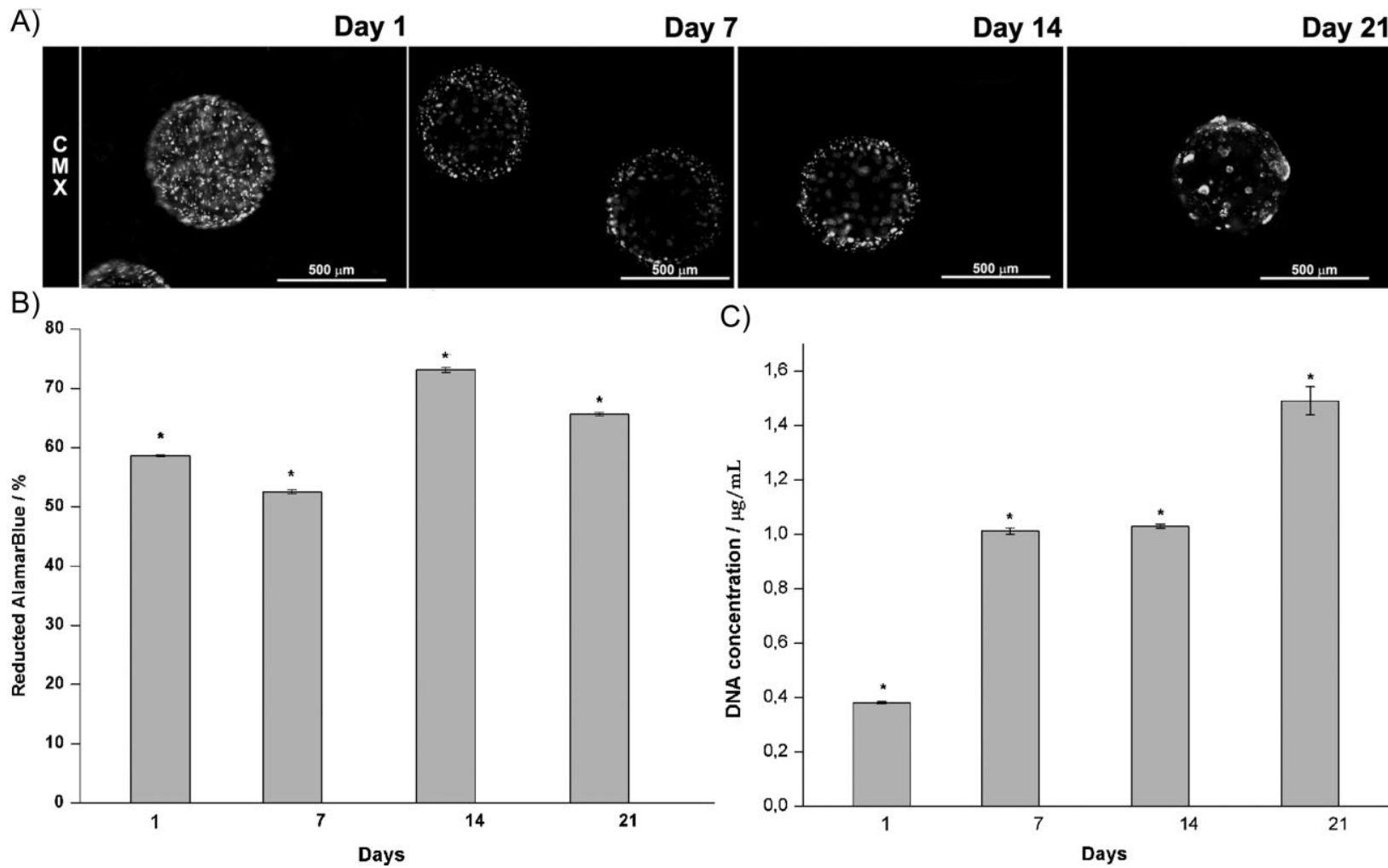

C)

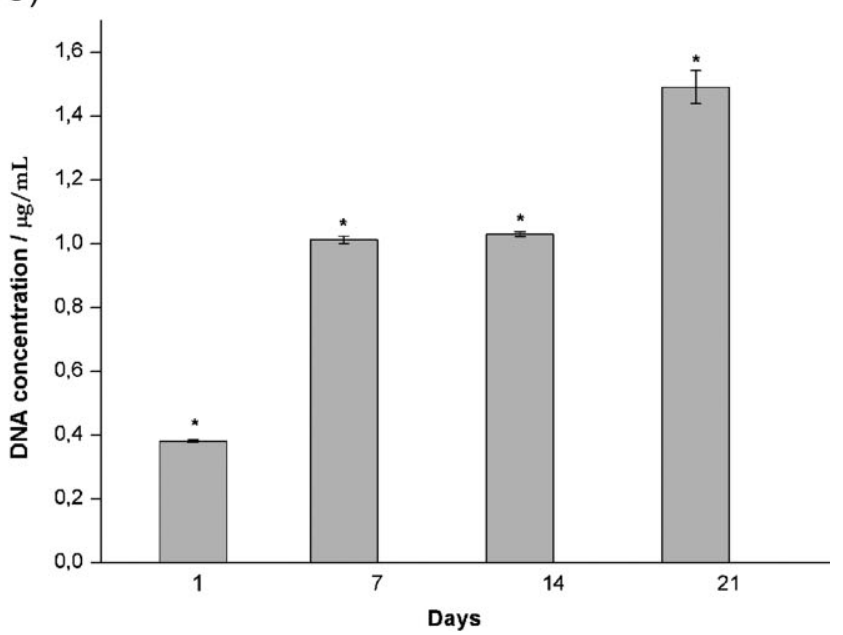

Figure 5. In vitro viability and proliferation of ATDC5 cells cultured in CMX microcapsules. (A) Fluorescence microscopy images displaying the live/dead assay of encapsulated cells (green cells are live, red cells are dead) showing that the cells remain viable in the microcapsules up to $21 \mathrm{~d}$ of culture. (B) Metabolic activity and (C) proliferation of encapsulated cells determined by AlamarBlue assay and DNA quantification. Results are expressed as means \pm standard deviation with $n=3 .{ }^{*}$ indicates significant difference $(p<0.05)$ between different time points for CMX microcapsules.

complete culture medium were used, respectively, as negative and positive controls. The results showed that the CMX capsules do not cause any deleterious change in the metabolic activity of ATDC5 cells and consequently CMX capsules can be considered safe for cell encapsulation.

\subsection{In vitro Viability and Proliferation of ATDC5 Cells Cultured within Microcapsules}

In vitro studies are necessary to ensure that CMX microcapsules did not cause cell death or inhibit cell proliferation.

The morphology (Figure 6A) and viability (Figure 5A and B) of encapsulated cells were investigated after several days in culture. Cells formed small aggregates with strong green fluorescence observed inside the capsule (Figure 5A), demonstrating high viability of ATDC5 cells post-encapsulation. Furthermore, an even cell distribution can be observed throughout the culturing time (Figure $5 \mathrm{~A}$ and 6A) in CMX microcapsules, but in the latest times (14 and 21 d), ATDC5 cells encapsulated in CMX showed their tendency to form cellular aggregates (Figure 5A) demon- strating a potential chondrogenic phenotypic behavior. SEM also revealed the formation of cell aggregation inside the capsules (Figure 7D and E).

The metabolic activity of ATDC5 cells was investigated throughout the culturing period using AlamarBlue assay (Figure 5B). The results showed that ATDC5 cells encapsulated in CMX matrix were able to reduce AlamarBlue over the $21 \mathrm{~d}$ of in vitro culture (Figure 5B).

To support the results provided from AlamarBlue assay, cell proliferation was investigated by DNA quantification. DNA quantification (Figure $5 \mathrm{C}$ ) revealed a steady and significant $(p<0.05)$ increase in the DNA amounts with culturing time as a result of improved cellular proliferation in CMX microcapsules. A common limitation of polyelectrolyte complexes is lack of permeability to larger molecules, such as proteins, because these systems are normally characterized by a dense membrane structure. ${ }^{\text {[42] }}$ The ATDC5 cells remained viable within microcapsules for up to 3 weeks in culture. The CMX microcapsules could therefore provide sufficient nutrient diffusion necessary for cell survival and proliferation.

ATDC5 is a very well established cell line known to be an excellent in vitro chondrogenic model for determining

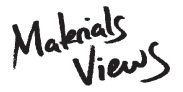

www.MaterialsViews.com 


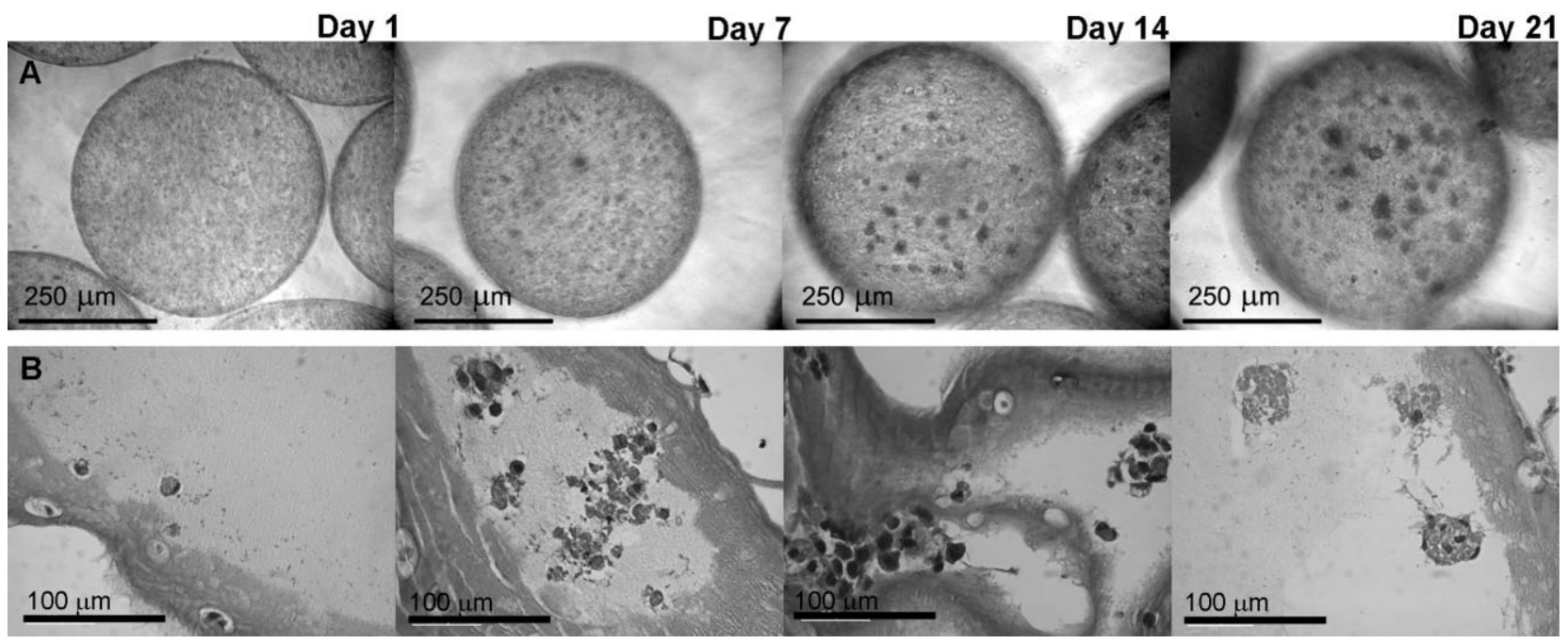

Figure 6. Bright field light microscopy images of (A) living cells encapsulated in CMX microcapsules and (B) microcapsule sections stained with $H \& E$ after different culturing times.
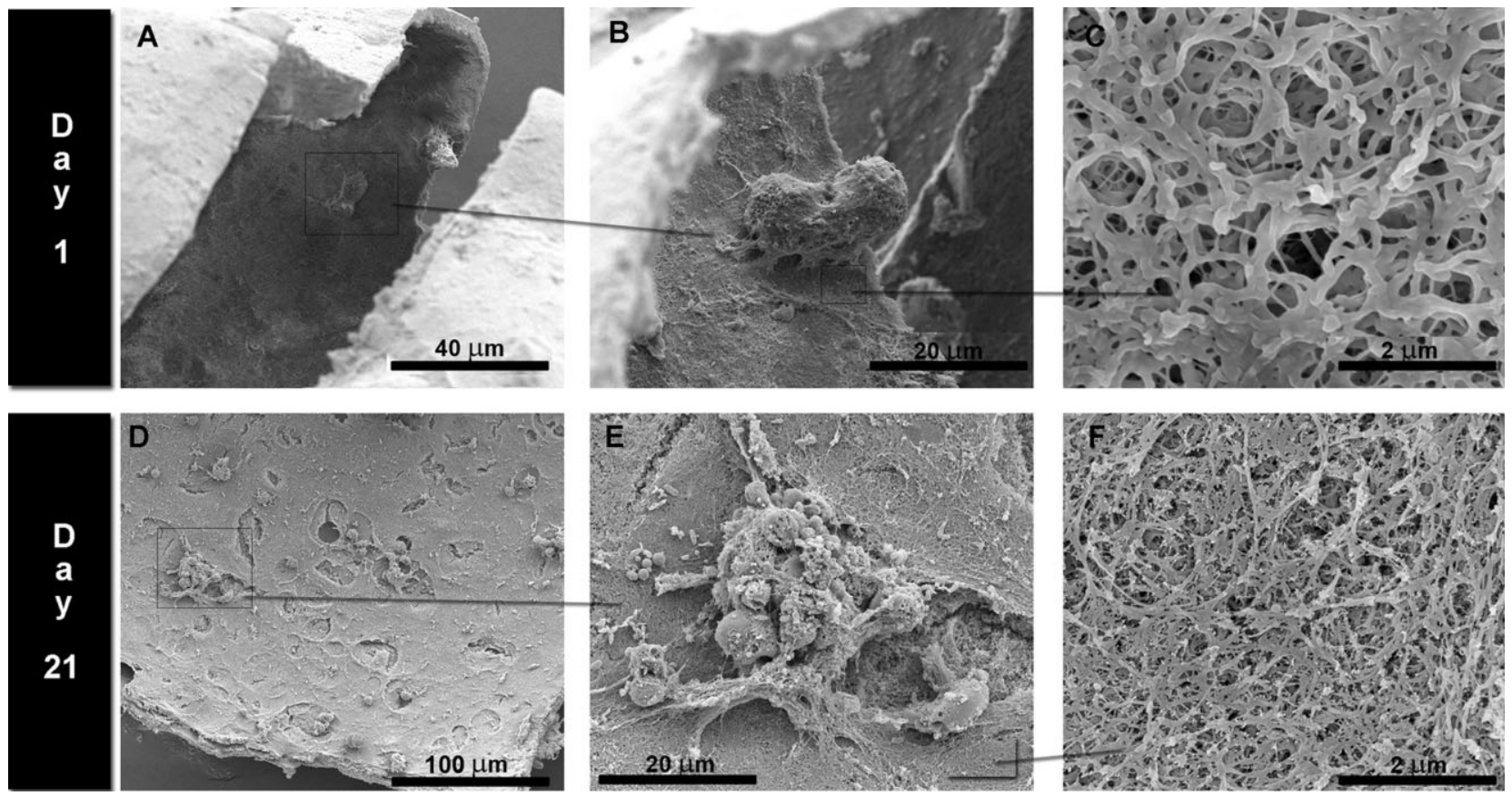

Figure 7. SEM images showing the interior of the CMX microcapsules after 1 and $21 \mathrm{~d}$ of culture. (A, B) Morphological characteristics of the cells attached to the microcapsule inner surface. (D, E) Cell aggregates formed after $21 \mathrm{~d}$ of culture. (C, F) Microstructure of the microcapsule inner surface showing highly porous structure (F).

events during chondrogenesis. ${ }^{[33-37]}$ Cell/matrix interactions during chondrogenesis are promoted by the 3D environment. ${ }^{[34]}$ In CMX microcapsules, ATDC5 cells retained their tendency to form cellular aggregates and they expressed high metabolic activity.

H\&E staining of cells encapsulated in the CMX microcapsules (Figure 6B) revealed that ATDC5 cells retained their rounded morphology throughout the culture time and tend to form cartilage nodule-like aggregates after $21 \mathrm{~d}$ of culture in the CMX microcapsules. This fact denotes that CMX microcapsules promoted the retention of the chondrocytic phenotype.

SEM analysis on cell cultured microcapsules revealed that the cells attached on the internal microcapsule surface, interact with the surrounding matrix by their extended filopodias (Figure 7B and E) and tend to form small 
aggregates over $21 \mathrm{~d}$ (Figure 7D and E). We speculate that the presence of ATDC5 cells and aggregates on the capsule wall may be a result of higher nutrient availability in these regions, since it is expected a better diffusion of nutrients near the capsule wall surface. At higher magnification, SEM image (Figure 7F) shows a fibrillar microstructure typical of natural ECM. Such fibrillar structure may offer additional advantages, when compared to the dense structure of other systems used for producing capsules, as it might allow a better control over capsule permeability.

In the current work, we have used a standard cell line to evaluate the ability of CMX microcapsules to support cell viability and proliferation. Given these encouraging preliminary results, we envision the encapsulation of human articular chondrocytes in CMX to be applied as cell-based therapies in cartilage tissue engineering approaches.

\section{Conclusion}

This study presents a novel process that utilizes a microdroplet generator to prepare microcapsules using the xanthan gum polysaccharide. The optimized process conditions enabled generating microcapsules with longterm stability and the encapsulation of a chondrocytic cell line. Encapsulated cells showed high viability (the cells survive in culture for at least 3 weeks) and retained the property of forming cell aggregates. In conclusion, our studies suggest that $\mathrm{CMX}$ can be an alternative to the current cell encapsulating materials, but in vivo studies are necessary to confirm our hypothesis. Nonetheless, CMX microcapsules may offer significant potential for long term cell culture in bioreactors for applications in cell therapies.

Acknowledgements: This work was supported through the European Union funded project "Find and Bind" (NMP4-SL2009-229292) under FP7. A. C. M. thanks the Portuguese Foundation for Science Technology for a PhD grant (SFRH/BD/ 42161/2007). We thank Prof. Manuel Coimbra and Dr. Claudia Nunes from Aveiro University for their assistance with xanthan molecular weight determination.

Received: August 3, 2011; Revised: September 22, 2011; Published online: DOI: 10.1002/mabi.201100304

Keywords: cell delivery; microdroplet generator; microencapsulation; polysaccharides; xanthan gum

[1] S. R. Bhatia, S. F. Khattak, S. C. Roberts, Curr. Opin. Colloid Interface Sci. 2005, 10, 45.

[2] S. S. Maria-Engler, M. Mares-Guia, M. L. C. Correa, E. M. C. Oliveira, C. A. M. Aita, K. Krogh, T. Genzini, M. P. Miranda,
M. Ribeiro, L. Vilela, I. L. Noronha, F. G. Eliaschewitz, M. C. Sogayar, Braz. J. Med. Biol. Res. 2001, 34, 691.

[3] F. Lim, A. M. Sun, Science 1980, 210, 908.

[4] J. T. Wilson, E. L. Chaikof, Adv. Drug Delivery Rev. 2008, 60, 124.

[5] G. Orive, A. R. Gascón, R. M. Hernández, M. Igartua, J. Luis Pedraz, Trends Pharmacol. Sci. 2003, 24, 207.

[6] P. de Vos, M. Bucko, P. Gemeiner, M. Navrátil, J. Svitel, M. Faas, B. L. Strand, G. Skjak-Braek, Y. A. Morch, A. Vikartovská, I. Lacík, G. Kolláriková, G. Orive, D. Poncelet, J. L. Pedraz, M. B. Ansorge-Schumacher, Biomaterials 2009, 30, 2559.

[7] I. E. Raschip, I. Yakimets, C. P. Martin, S. S. Paes, C. Vasile, J. R. Mitchell, Powder Technol. 2008, 182, 436.

[8] N. Wang, G. Adams, L. Buttery, F. H. Falcone, S. Stolnik, J. Biotechnol. 2009, 144, 304.

[9] X-t. Mo, S-c. Guo, H-q. Xie, L. Deng, W. Zhi, Z. Xiang, X-q. Li, Z-m. Yang, Bone 2009, 45, 42.

[10] M. Hsiao-Li, H. Shih-Chieh, L. Shan-Yang, C. Yuh-Lien, L. Wai-Hee, J. Biomed. Mater. Res. 2003, 64A, 273.

[11] E. B. Hunziker, Osteoarthritis Cartilage 2002, 10, 432.

[12] J. Fan, Y. Gong, L. Ren, R. R. Varshney, D. Cai, D.-A. Wang, Acta Biomater. 2010, 6, 1178.

[13] B. Peter, D. Meng, C. Denis, G. Michael, G. Klaus-Peter, F. Stefan, Biotechnol. Prog. 2009, 25, 1146.

[14] H. Park, J. S. Temenoff, T. A. Holland, Y. Tabata, A. G. Mikos, Biomaterials 2005, 26, 7095.

[15] A. Murua, A. Portero, G. Orive, R. M. Hernández, M. de Castro, J. L. Pedraz, J. Controlled Release 2008, 132, 76.

[16] H. Uludag, P. De Vos, P. A. Tresco, Adv. Drug Delivery Rev. 2000, 42, 29.

[17] A. Murua, G. Orive, R. M. Hernández, J. L. Pedraz, J. Controlled Release 2009, 137, 174.

[18] T. M. S. Chang, Nat. Rev. Drug Discovery 2005, 4, 221.

[19] R. C. Pereira, M. Scaranari, P. Castagnola, M. Grandizio, H. S. Azevedo, R. L. Reis, R. Cancedda, C. Gentili, J. Tissue Eng. Regen. Med. 2009, 3, 97.

[20] P. D. Benya, J. D. Shaffer, Cell 1982, 30, 215.

[21] M. M. Stevens, H. F. Oanadilo, R. Langer, V. Prasad Shastri, Biomaterials 2004, 25, 887.

[22] L. Francois, S. Nathalie, G. Caroline Le, D. Sylvie, A. Monique, J. Cell. Physiol. 1998, 176, 303.

[23] R. S. Tare, P. A. Townsend, G. K. Packham, S. Inglis, R. O. C. Oreffo, Bone 2008, 42, 113.

[24] P. D. Vos, B. J. D. Haan, G. H. J. Wolters, J. H. Strubbe, R. V. Schilfgaarde, Diabetologia 1997, 40, 262.

[25] B. Katzbauer, Polym. Degrad. Stab. 1998, 59, 81.

[26] F. García-Ochoa, V. E. Santos, J. A. Casas, E. Gómez, Biotechnol. Adv. 2000, 18, 549.

[27] C. Schorsch, C. Garnier, J.-L. Doublier, Carbohydr. Polym. 1995, 28,319 .

[28] M. Hamcerencu, J. Desbrieres, M. Popa, A. Khoukh, G. Riess, Polymer 2007, 48, 1921.

[29] I. Capron, G. Brigand, G. Muller, Polymer 1997, 38, 5289.

[30] A. B. Rodd, D. E. Dunstan, D. V. Boger, Carbohydr. Polym. 2000, 42, 159.

[31] J. T. Oliveira, T. C. Santos, L. Martins, M. A. Silva, A. P. Marques, A. G. Castro, N. M. Neves, R. L. Reis, J. Tissue Eng. Regen. Med. 2009, 3, 493.

[32] A. C. Mendes, E. T. Baran, C. Nunes, M. A. Coimbra, H. S. Azevedo, R. L. Reis, Soft Matter 2011, 7, 9647.

[33] C. Shukunami, C. Shigeno, T. Atsumi, K. Ishizeki, F. Suzuki, Y. Hiraki, J. Cell Biol. 1996, 133, 457.

[34] R. S. Tare, D. Howard, J. C. Pound, H. I. Roach, R. O. C. Oreffo, Biochem. Biophys. Res. Commun. 2005, 333, 609.

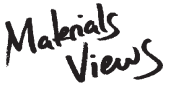

www.MaterialsViews.com
Macromol. Biosci. 2011, 11, 000-000

(C) 2011 WILEY-VCH Verlag GmbH \& Co. KGaA, Weinheim

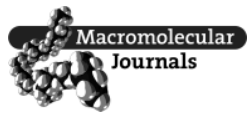


[35] T. Atsumi, Y. Ikawa, Y. Miwa, K. Kimata, Cell Differ. Dev. 1990, 30, 109.

[36] H. Akiyama, C. Shukunami, T. Nakamura, Y. Hiraki, Cell Struct. Funct. 2000, 25, 195.

[37] C. Phornphutkul, K.-Y. Wu, X. Yang, O. Chen, P. A. Gruppuso, J. Endocrinol. 2004, 183, 477.

[38] X.-G. Chen, H.-J. Park, Carbohydr. Polym. 2003, 53, 355.
[39] H.-C. Ge, D.-K. Luo, Carbohydr. Res. 2005, 340, 1351.

[40] E. T. Baran, A. C. Mendes, H. S. Azevedo, R. L. Reis, PT 105489, 2011.

[41] I. Ghidoni, T. Chlapanidas, M. Bucco, F. Crovato, M. Marazzi, D. Vigo, M. Torre, M. Faustini, Cytotechnology 2008, 58, 49.

[42] K. Ohkawa, T. Kitagawa, H. Yamamoto, Macromol. Mater. Eng. 2004, 289, 33. 